\title{
Diffusion Factors of Coronary Artery Disease: A Comparative Study of 130 Patients
}

\author{
Asmaa Goulahsen*, Joumana El Masrioui, Abdelkarim Ait Yahya, Hasna Ait ELHadj, Dounia Benzarouel, Mustapha El
} Hattaoui

Cardiology Department, Arrazi Hospital, University Hospital Center Mohammed VI, Marrakech

DOI: $10.36347 /$ sjmcr.2020.v08i02.006

| Received: 27.01.2020 | Accepted: 03.02.2020 | Published: 08.02.2020

*Corresponding author: Goulahsen Asmaa

Abstract

Original Research Article

\begin{abstract}
Multivessel coronary artery disease is usually defined by the presence of angiographic stenosis over $50 \%$ in at least two of the three epicardic coronary truncs. This multivessel lesion is associated with pejorative prognosis, particularly in case of proximal anterior interventricular artery (proximal LAD) stenosis and/or left ventricular dysfunction [1]. The aim of our study is to compare the epidemiological, clinical and angiographic particularities of multivessel coronary patients with single vessel patients in order to suggest the different predictive factors of coronary lesion diffusion and to identify high risk patients in need of special attention and new therapeutic strategies. We conducted a transversal and descriptive study on over 130 patients, between January 2016 to January 2017, at the catheterization laboratory in the cardiology and vascular diseases department of university hospital Mohamed 6 in Marrakech. The prevalence of multivessel coronary artery disease was $40 \%+/ 4 \%$. In a bivariate analysis only age, diabetes and smoking were predictive of multivessel lesions. A multidisciplinary approach resting on clinical and angiographic scores is actually the cornerstone in the decision-making process to provide medical management of multivessel coronary lesions.

Keywords: Multivessel coronary artery disease, predictive factors, Diffusion, atherosclerotic, diabetes.

Copyright @ 2020: This is an open-access article distributed under the terms of the Creative Commons Attribution license which permits unrestricted use, distribution, and reproduction in any medium for non-commercial use (NonCommercial, or CC-BY-NC) provided the original author and source are credited.
\end{abstract}

\section{INTRODUCTION}

Multivessel coronary artery disease is usually defined as the presence of angiographic stenosis over $50 \%$ in at least two of three epicardic coronary truncs. This multivessel lesion is associated to a pejorative prognosis, especially in case of proximal LAD and/or left ventricular dysfunction [1]. Patients presenting with multivessel lesions are known to be older, having more comorbidities, cumulating multiple cardiovascular risks. The diffused and aggressive atherosclerotic lesions expose to myocardial ischemia [2]. Patients usually have a left ventricular dysfunction, and it darkens the prognosis.

The purpose of our study is to compare the epidemiological, clinical and angiographic particularities of multivessel coronary patients with single vessel patients in order to suggest the different predictive factors of coronary lesion diffusion and to identify high risk patients in need of special attention and new therapeutic strategies.

\section{Material AND Methods}

We conducted a transversal and descriptive study on over 130 patients, between January 2016 to January 2017, at the catheterization laboratory in the cardiology and vascular diseases department of university hospital Mohamed 6 in Marrakech.

We had integrated all patients explored with coronarography, including these criteria's: typical or atypical angina, dilated cardiomyopathy etiology examination, and post myocardial infarction examination. Therefore, we have excluded, valvular heart patients undergoing preoperative coronary angiography.

\section{RESULTS}

\section{a) Epidemiology}

The prevalence of multivessel coronary artery disease was $40 \%+/-4 \%$.

The age average of multivessel population was $62+/-8$ hears with a male predominance of $63 \%$. 
Table-1: Diffusion of coronary lesions according to age

\begin{tabular}{|c|c|c|c|}
\hline & Multivessel lesions & single vessel lesions & P value \\
\hline Average age in years & $62+/-8$ & $58+/-9$ & 0.05 \\
\hline
\end{tabular}

Table-2: distribution according to sex

\begin{tabular}{|c|c|c|}
\hline Sex & Multivessel lesions & single vessel lesions \\
\hline Male & $\mathbf{3 3}(\mathbf{6 3 \%})$ & $\mathbf{3 1}(\mathbf{7 0 , 5 \% )}$ \\
\hline Female & $\mathbf{1 9}(\mathbf{3 7 \%})$ & $\mathbf{1 3 ( 2 9 , 5 \% )}$ \\
\hline Total & $\mathbf{5 2 ( 1 0 0 \% )}$ & $\mathbf{4 4 ( 1 0 0 \% )}$ \\
\hline
\end{tabular}

\section{b) Cardiovascular risk factors}

The cardiovascular risk factors was dominated with diabetes $(65,4 \%)$, smoking $(61,5 \%)$, high blood pressure $(60 \%)$, and obesity in $60 \% .63,5 \%$ of patients had more than 3 cardiovascular risk factors.

Table-3: Diffusion of coronary lesions according to cardiovascular risk factors

\begin{tabular}{|l|ll|ll|l|}
\hline & \multicolumn{3}{|l|}{ Multivessel lesions } & \multicolumn{3}{|l|}{ single vessel lesions } & P value \\
\hline High-blood pressure & 31 & $(60 \%)$ & 22 & $(50 \%)$ & NS \\
\hline Diabetes & 34 & $(65,40 \%)$ & 19 & $(43,2 \%)$ & 0.029 \\
\hline Smoking & 32 & $(61,50 \%)$ & 17 & $(38,6 \%)$ & 0,025 \\
\hline Dyslipidaemia & 24 & $(46,20 \%)$ & 19 & $(43,2 \%)$ & Ns \\
\hline Obesity & 31 & $(60 \%)$ & 22 & $(50 \%)$ & Ns \\
\hline Menopause & 19 & $(37 \%)$ & 12 & $(27,3 \%)$ & Ns \\
\hline$>3$ CvxRF & 33 & $(63,50 \%)$ & 20 & $(45,5 \%)$ & Ns \\
\hline
\end{tabular}

\section{c) Comorbidities}

$19,2 \%$ of patients having renal failure have multivessel lesions vs $9.1 \%$ of single vessels, this difference are not significant.
$13.5 \%$ of patients presenting with anaemia were multivessel vs $4,5 \%$ of single vessels, with a nonsignificant statistic difference.

$5.8 \%$ of patients that were followed for a chronic obstructive pulmonary disease had presented multivessel coronary lesion vs $6.8 \%$ of single vessels.

Table-4: Distribution of comorbidities in the 2 groups of patients

\begin{tabular}{|l|l|l|l|}
\hline & Multivessel lesions & single vessel lesions & P value \\
\hline Renal failure & $19.2 \%$ & $9,1 \%$ & NS \\
\hline Anaemia & $13,5 \%$ & $4,5 \%$ & NS \\
\hline Chronic obstructive pulmonary disease & $5,8 \%$ & $6,8 \%$ & NS \\
\hline
\end{tabular}

\section{d) Clinical presentation}

The multivessel status was discovered after chronic coronary syndrome in $83 \%$ of cases. Dyspnea was associated in $67,3 \%$ of cases and in $15,4 \%$ of cases.

\section{e) Transthoracic echocardiography findings}

The echocardiography found a preserved left ventricular systolic function $(\mathrm{LVEF}>50 \%)$ in single vessels $(52.73 \%+/-9.5 \%$ vs $49 \%+/-11.8 \%$ in multivessels; $\mathrm{p}$ value non-significant)

$47.1 \%$ of patients having e LVEF $<50 \%$ have presented multivessel lesions vs $26.8 \%$ of single vessels, this difference was statistically signinficant $(\mathrm{p}=$ 0,047 )

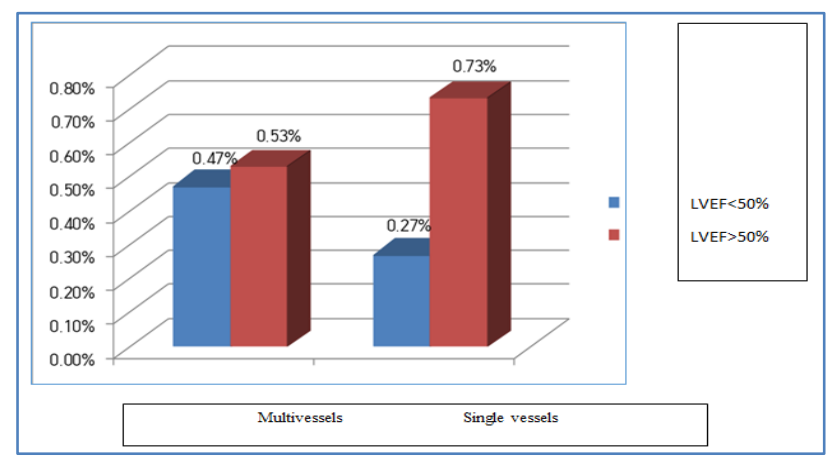

Fig-1: A graphic comparing LVEF in the 2 groups of patients according to LVEF 
We noticed a kinetic disorder in $70.6 \%$ of patients having multivessel lesions vs $59,1 \%$ in single vessels group. Moreover, complications such as ischaemic mitral regurgitation was present in $33.3 \%$ multivessels vs $20,5 \%$ in single vessels, left ventricular dilatation was found in $7,7 \%$.

Table -5: Echocardiography findings

\begin{tabular}{|l|l|l|}
\hline & Multivessel group & Single vessel group \\
\hline LVEF & $49+/-11,8 \%$ & $52,73+/ \_9,5 \%$ \\
\hline Kinetic disorder & $33,3 \%$ & $20,5 \%$ \\
\hline Mitral regurgitation & $70,6 \%$ & $59,1 \%$ \\
\hline
\end{tabular}

\section{f) Angiography findings}

The coronary status evaluation findings were triple vessel lesions predominance in $31 \%$ of patients and two vessel lesions in $9 \%$ of cases. The lesions of left anterior descending artery was found in both groups, however it was present in $94,2 \%$ of the multivessel group In which $63,5 \%$ were in mild segment vs $72,7 \%$ of single vessels. Followed by, right coronary artery lesions in $86,5 \%$ vs $25 \%$ of single vessels and circumflex artery in $71,2 \%$ vs $15,9 \%$ in single vessels cases.
Type B/C lesions were found in $47 \%$ of cases with high proportion of calcifications up to $(50 \%)$ in multivessels vs $20.5 \%$ in single vessels group. We found in multivessels long lesions in $(65,4 \%)$, chronic occlusions (79\%) vs respectively $29,5 \%$ and, $14,5 \%$ in single vessels group.

\section{g) Therapeutic management}

After coronary angiography, only medical treatment was started in $7.7 \%$ in cases. Angioplasty procedure was indicated in $42,3 \%$ with Drug-eluting stent in $59 \%$. In $28,8 \%$ of cases the revascularization was surgical using $\mathrm{CAB}$ graft.

Table-6: Comparing therapeutic management in both groups

\begin{tabular}{|l|l|l|}
\hline & Multivessel group & single vessel group \\
\hline Medical strategy alone & $7,7 \%$ & $18,2 \%$ \\
\hline Medical treatment +angioplasty & $42,3 \%$ & $77,3 \%$ \\
\hline Medical treatment + CABG & $28,8 \%$ & $4,5 \%$ \\
\hline
\end{tabular}

\section{DISCUSSION}

The extension of lesions is an important prognosis factor in coronary patients; causing specific problems in term of revascularization, due to the number of sites to treat. The epidemiological studies demonstrated that multi vessel CAD patients had high risk of mortality in comparison with single vessel patients, with an increased mortality risk if associated to left ventricular dysfunction [3, 4]; thus, they must be identified for therapeutic implications. Clinical parameters and non-invasive examination could predict the patients at risk of diffuse coronary artery disease.

\section{Predictive elements of multi vessel coronary artery disease \\ Age}

In our study, the average of our multi vessel coronary artery disease patients age was $62+/-8$ years vs 58+/9 years in single vessel patients, with a significant statistic difference $(\mathrm{p}=0,05)$; this result is similar to most published studies.

\section{Cardiovascular risk factors}

In our study, diabetes and smoking are the main risk factors related to multi vessel lesions, compared to single vessels $(65,4 \%, 61,5 \%$, versus $43,2 \%, 38,6 \%$ with a significant $\mathrm{p}$ value) the different risk factors of atherosclerosis have low predictive value of multivessel coronary artery disease[5]. However other studies, found that the inherited genetic susceptibility of coronary artery disease was the risk factor independently of others, and had the highest predictive value $62 \%$ of multivessel coronary artery disease [6].

\section{LVEF}

In our study $47,1 \%$ of multivessel patients had a LVEF $<50 \%$ versus $26,8 \%$ of single vessel patients, this difference was statistically significant $(\mathrm{p}=0,047)$, we concluded that a low LVEF is associated to a multivessel coronary artery disease.

Others

Other parameters were evaluated in other studies, particularly, residual angina, myocardial ischemia tests such as exercise stress test and myocardial scintigraphy. These studies concluded that patients with residual angina had more multivessel lesions than asymptomatic patients in $79 \%$ versus $45 \%$ [7]. Whereas in others, residual angina had no predictive value of multivessel coronary artery disease $[8,9]$. In review of literature, negative maximal exercise stress test is highly predictive of the absence of multi vessel coronary artery disease $[6,10,11]$. 


\section{Conclusion}

Multivessel coronary artery disease constitutes a particular entity in terms of their anatomy, physiopathology, clinical expression, angiographic status and the therapeutic management.

The Multivessel coronary artery disease of our study is characterized by: Advanced age, aggressive and diffuse atherosclerotic lesions, the association with comorbidities, and a high cardiovascular risk score, a higher rate of diabetic patients, and stable angina as a dominant clinical feature. A severe angiographic assessment with higher proportion of calcifications, type B2/C lesions, long lesions and chronic occlusions.

The therapeutic management was based on different techniques of myocardial revascularization. The diffusion of coronary lesions is an important prognostic factor. The identification of the predictive elements of multivessel lesions makes it possible to identify a subgroup of high risk patients, who can benefit from special attention and new therapeutic strategies. Only age, diabetes and smoking seem to be predictive of multivessel involvement in our study.

\section{REFFERENCE}

1. Habib Ben Ahmed, Imen hamdi, Houssem Boussaid, Rym Ben Romdhane, Salma Loungou, Mohamed Rachid Boujnah. Les résultats à moyen terme de l'angioplastie coronaire chez les multitronculaires dans des « conditions de vie réelle ». Service de Cardiologie Hopital Mongi Slim La Marsa -Tunis -Tunisie

2. Olivier Varenne. Revascularisation des patient's pluritronculaires. Eléments de decision .Hôpital Cochin Université Paris V René Descartes.11.3012.30 ERCREDI 19 NOV 2014

3. Friesinger CG, Page EE, Ross RS. Prognostic signifance of coronary artériography. Trans. Assoc. Am. Physicians. 1970, 83: 78-92

4. Miller Richard R, DE Maria Anthony N, Vismara L, Salel AF, Maxwell K, Amsterdam Ezra A,
Mason D. Chronic stable inferior myocardial infarction: unspected harbinger of high risk proximal left coronary arterial obstruction amenable to surgical revascularisation. Am. J. Cardiol. 1977, 39: 754-760

5. Laffay N, Aubry P, Akesbi A, Zouioueche S, Marcadet D, Tellier Ph, Haddad A, Guerot C, Gryman R, Valere PE. Dépistage d'une atteinte de l'interventriculaire antérieure après primoinfarctus postérieur.Arch. Mal. Coeur. 1984, 78: 1141-1147.

6. Drissa H, Zaouali RM, Meddeb I, Kafsi N. Abid F, Ben Ismail M. Diffusion des lesions coronaires et dépistage des atteintes tritronculaires dans l'infarctus postérieur. Médecine du Maghreb. 1991 $\mathrm{n}^{\circ} 29$

7. Defeyter PJ, Eenige MJ, Dighton DH, Visser FC, DE Jong J, Roos JP. Prognostic value of exercice testing, coronary angiography and left ventriculography 6-8 weeks after myocardial infarction.Circulation. 1982, 66:527-536.

8. Machecourt J, Denis B, Bouvagnet P, Wolf JE, Page E, Therraube Ph, Comet M. Les méthodes non traumatiques peuvent-elles prédire l'existence d'une sténose de l'interventriculaire antérieure après primoinfarctus postéroinférieur ? Arch. Mal. Coeur. 1982, 12: 1347-1355

9. Moise A, Fournier Cl, Barriclon A, Fernandez F, Saudemont JP, Raissis M, Gerbaux A. Le dépistage des atteintes multitronculaires après un primoinfarctus myoscardique postérieur.Ann Cardiol. Angeiol. 1981, 30: 237.

10. Castellanet MJ, Greenber G PS, Ellestaed HH. Comparison of ST changes on exercise testing with angiographic findings in patients with prior myocardial infarction. Am. J. Cardial. 1978, 42: 29.

11. Machecourt J, Denis B, Bouvagnet P, Wolf J, Page Z. Les méthodes non effractives peuvent-elles prédire l'existence d'une sténose de l'interventriculaire antérieur après primoinfractus inférieur? In. Communication de la Société Française de Cardiologie, Paris. 1981. 